\title{
Effect of Mixing Time to Homogeneity of Propellant Slurry
}

\author{
Luthfia H. Abdillah ${ }^{1}$, Sugeng Winardi ${ }^{1}$, Sumarno ${ }^{1}$, Tantular Nurtono ${ }^{1}$
}

\begin{abstract}
Propellant is a rocket fuel that can be solid or liquid. This research focused on composite solid propellant that was made from solid and liquid materials become a slurry. Homogeneity of the propellant slurry is important to investigate because it can affect specification and performance of the propellant. This research objective was to study effect of mixing time to homogeneity of propellant slurry that was processed by horizontal sigma blade mixer. Density data were used to assess the homogeneity and stated as degree of homogeneity. The result showed that the mixing time affect the density values and it was obtained the most homogeneous slurry was at total mixing time 135 minutes.
\end{abstract}

Keywords-Homogeneity, Mixing Time, Propellant Slurry, Sigma Blade Mixer.

\section{INTRODUCTION}

Propellant is a rocket fuel that can be solid or liquid form. The solid propellant can be single base, double base or composite propellant. The composite solid propellant is made from oxidizer crystals and fuel powder and mixed together in binder matriks.

Some type of hydrocarbon binder are PBAN (poly(butadiene-acrylonitrile)), PBAA (poly (butadieneacrylic acid)), CTPB (carboxyterminated poly(butadiene)) and HTPB (hidroxy terminated poly(butadiene)). HTPB as the binder system showed its worthiness superiority over other binders in line in the sense that it was found capable of very high solids loading (86 wt\% - $90 \mathrm{wt} \%$ ) without sacrificing the ease in processability and that too with improved mechanical properties and enhanced internal ballistic characteristics [1]. Propellant slurry is cured by crosslinking or polymer binder cured by a little of curing agent, then cured in the oven until solidified and hardened [2]. Physical and mechanical properties of propellant was affected by liquid materials because one of binder specification is giving its mechanical specification into the propellant [3].

To make propellant as specified requirement, it need to mix all raw materials become slurry by using an equipment, mixer. The specifications of propellant can be obtained as requirement by adjusted its composition. So, it is important to have some investigation to make sure that the propellant

\footnotetext{
${ }^{1}$ Luthfia H. Abdillah, Sugeng Winardi, Sumarno, and Tantular Nurtono are with Department of Chemical Engineering, Faculty of Industrial Engineering, Institut Teknologi Sepuluh Nopember (ITS), Kampus ITS Sukolilo, Surabaya 60111, Indonesia. E-mail: luthfia15@mhs.chemeng.its.ac.id; swinardi@chem-eng.its.ac.id; onramus@chem-eng.its.ac.id; tantular@chem-eng.its.ac.id.
}

slurry is mixed thoroughly in the mixer and produce a homogeneous slurry.

Some factors that affected the slurry homogeneity can be mixing time, mixing speed, mixing temperature, raw materials type, sequence of materials, and some other factors. It needs to assess the homogeneity of the propellant slurry. There are not many article discuss about slurry homogeneity specifically, mostly is discussing about homogeneity of powder mixing. This article provided an information about effect of mixing time in the propellant slurry homogeneity and provide an overview about optimum process condition that produced the most homogeneous slurry processing by horizontal sigma blade mixer.

Solid propellant is classified into two type i.e single/double base propellant and composite propellant. Composite propellant development is intended to increase the thrust of propellant than single/double base propellant [4]. Composite propellant is made of solid and liquid materials mixed thoroughly in the mixer.

There are two type of mixer for propellant and explosive materials i.e vertical and horizontal type of mixer. Vertical mixers have some type of blade such as paddle, double impeller, and triple impeller, while the horizontal can be single sigma blade or double sigma blade. The Z-blade (or sigma blade) mixer is commonly used for pastes as well as powder [5].

In conventional powder-mixing operations, a perfectly homogeneous mixture is defined such that the powder component under investigation becomes uniform throughout the mixture [6]. A first and obvious proposal to assess the state of a mixture would be to measure a property of interest throughout the system (e.g., concentration of a key component) and to determine the magnitude of deviations in the sample values from the target value desired for the entire mixture [7]. Perfect mixture is when the concentration at any randomly selected point in the mix in a sample of whatever size is the same as that of the overall concentration [8].

Statistics are used widely to define the degree of mixedness (the degree of homogeneity) for a powder mixture [6]. Standard deviation of the distribution, s, is a measure of the quality of the mixture. A high quality mixture will show very little variation in composition between samples and will have a low standard deviation. If ' $\mathrm{n}$ ' samples are withdrawn from the batch, then

$$
s=\sqrt{\frac{\sum\left(\mathrm{y}_{\mathrm{i}}-\overline{\mathrm{y}}\right)^{2}}{(\mathrm{n}-1)}}
$$


The square of the standard deviation is the variance, $s^{2}$. This is widely used to typify particulate mixture quality because of its additive properties [5]. There is another measure that more appropriate than standard deviation to express diversity of a data set, that is coefficient of variance (cv), that defined as,

$$
c v=\frac{s}{\bar{x}} \times 100 \%
$$

it is express standard deviation as a percentage of the mean [9].

\section{EXPERIMENTAL}

\section{A. Materials}

Hydroxy-terminated polybutadiene (HTPB) as a binder is manufactured by free radical polymerization with molecular weight $=2300-2800 \mathrm{~g} / \mathrm{mol}$, hydroxyl value $=$ $47.1 \mathrm{mg} \mathrm{KOH} / \mathrm{g}$, polydispersity $=2.5$, viscosity at $30^{\circ} \mathrm{C}=$ 2000 - $3000 \mathrm{cP}$, density 0.8-0.9 g/ $\mathrm{cm}^{3}$. Ammonium perchlorate (AP) as an oxidizer was used in trimodal distributions having average particle size $200 \mu \mathrm{m}, 100 \mu \mathrm{m}$ and $50 \mu \mathrm{m}$ respectively with density value $=1.95 \mathrm{~g} / \mathrm{cm}^{3}$. Dioctyl adipate (DOA) with specific gravity $=0.926$, isophorone diisocyanate (IPDI) with density $=1.049 \mathrm{~g} / \mathrm{cm}^{3}$, aluminum powder $(\mathrm{Al})$ with mean diameter $=10 \mu \mathrm{m}$ were used as plasticizer, curing agent and fuel, respectively. Triphenyl bismuth (TPB) with density value $=1.585 \mathrm{~g} / \mathrm{cm}^{3}$ and Tepanol with density value $=1.1 \mathrm{~g} / \mathrm{cm}^{3}$ were used as curing catalyst and bonding agent respectively. All of the materials were procured from trade.

\section{B. Propellant slurry preparation}

Propellant slurry was carried out in batch system using horizontal sigma blade mixer (5 kg maximum capacity) as depicted in Figure 1, with 85\% solid loading consist of aluminium powder and AP particle with coarser to finer ratio 2:1:1 and a slightly part of TPB. The remaining 15\% is liquid materials (HTPB, DOA, Tepanol and IPDI).

This mixer had a single blade with rotational speed of 60 rpm. Temperature control is done through a jacketed hot water circulation to keep the slurry temperature at range 50$55^{\circ} \mathrm{C}$.

The mixing process was carried out in several steps. First step was mixing all liquid materials for 15 minutes except the curing agent, IPDI. Second step was mixing each solid materials during the time specified start with fine to coarse $\mathrm{AP}$ particles then followed by $\mathrm{Al}$ powder. Solid mixing time was the variable of this research, i.e 10, 15, 20, 25, 30, 35, and 40 minutes for each solid materials. So, total mixing time of the process can be determined as 95, 115, 135, 155, 175, 195 and 215 respectively. Last, IPDI was added to mixture and mixed for 40 minutes, then this slurry termed as final mixing product.

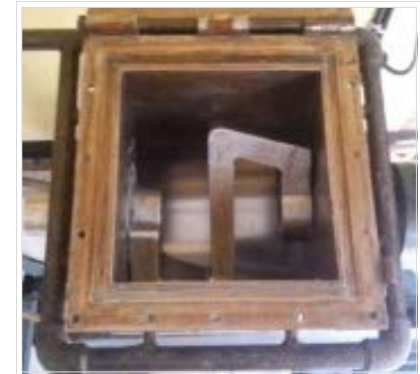

Figure 1. Horizontal Sigma Blade Mixer.

\section{Measurement of homogeneity}

Homogeneity of the slurry final mixing product was found by density data of the propellant slurry and solid propellant. Six locations in the mixer were selected for sampling i.e in the blade, in the four corners of the mixer and in the middle of mixer which was coded by $\mathrm{B}, \mathrm{SA}, \mathrm{SB}, \mathrm{SC}, \mathrm{SD}$, and $\mathrm{T}$ respectively, as illustrated in Figure 2. All sample taken was the surface part of the slurry in the mixer.

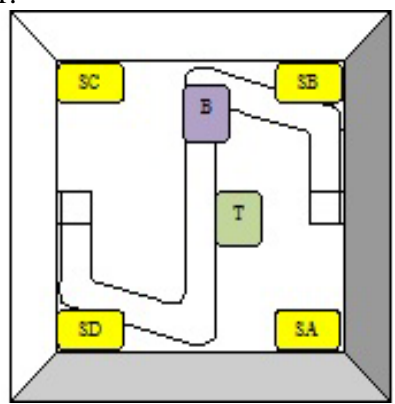

Figure 2. Sampling location on top view of mixer.

To measure the density, slurry of final mixing product was taken and put into two slab for each location. A seri of slab (six slabs) was for propellant slurry density measurement (direct measurement), and the other was for solid propellant density measurement (slurry was cured first become solid sample).

Five samples was taken of each slab for measuring propellant slurry density and solid propellant density. Measuring the propellant slurry density was by weighing slurry sample in well-known volume of the mini slab, termed as propellant slurry density. Measuring the solid propellant density was by curing the slurry final mixing product in oven at $80{ }^{\circ} \mathrm{C}$ for 24 hours then cut the sample into five pieces for each location, termed as solid propellant density. The solid propellant density was measured by instrumentation, called densitometer. The sample were showed in figure 3 (a) and (b).

Statistical method was used to assess the homogeneity. First, used one way anova to found the significance of density value differences at specified mixing time. Next, if it was found significantly different, then investigate the coefficient of variance to assess the homogeneity and found the optimum condition. 
The $3^{\text {rd }}$ International Seminar on Science and Technology August $3^{\text {rd }}$ 2017, Postgraduate Program Institut Teknologi Sepuluh Nopember, Surabaya, Indonesia

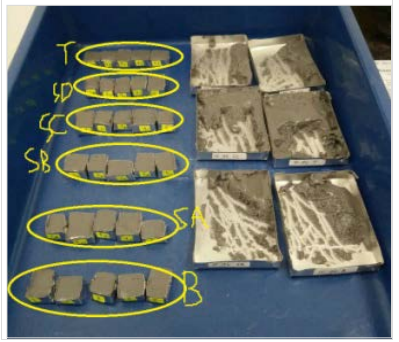

(a)

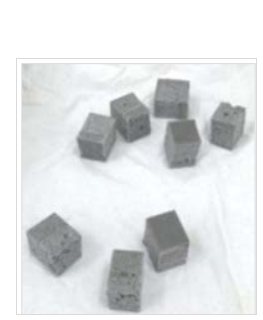

(b)
Figure 3. Sample for density measurement of (a) propellant slurry and (b) solid propellant.

\section{RESULTS AND DISCUSSION}

A slurry is a mixture of a liquid and solid particles. In most slurries, the liquid phase is water. However, coal-oil and coal-methanol fuels are examples of slurries made up with liquids other than water [10].

A mixture quality is important to investigate to assess that the mixture is perfectly mixed to get a homogeneous product. The most common way to assess the state of mixture or solution was by the value of concentration or its deviation from the desired concentration [7]. In case of propellant slurry, it can be stated homogeneous when all materials (solids and liquids) were well distributed in the product or it has the same composition in each part of the product. A good mixing result is when all solid particles are mixed each other and be covered by the liquid binder.

Solid mixing time was used as variable of this work to ensure that every solid materials can be well covered by the liquid materials. The mixing process of each solid materials become a special concern because the solids are the major materials of the mixture. To minimize the possibility of unmixed solids as showed in figure 4, manual attempt was conducted. This condition could occur when the mass of fine solid particles are more than the coarse particles.

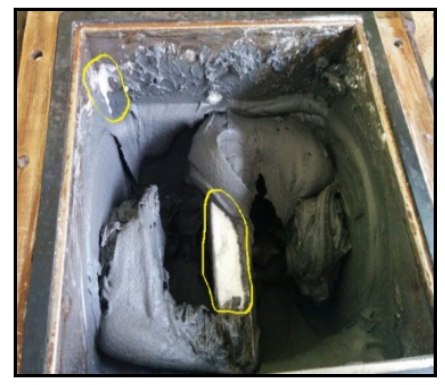

Figure 4. Unperfect mixing of the solids.

For determining the composition in each part was the same, density data were measured as a substitute of concentration data because the density range were wide enough among the solid and liquid materials, i.e 0.8 to 2.7 $\mathrm{g} / \mathrm{ml}$, so it was assumed that it can substitute the concentration data. The homogeneous propellant slurry was the slurry with density values in each part of mixer were similar or relatively same. The mean of propellant slurry density and solid propellant density in each location were showed in table 1 and table 2, respectively.
TABLE 1.

DATA RESULT OF PROPELLANT SLURRY DENSITY

\begin{tabular}{ccccccc}
\hline \hline \multirow{2}{*}{$\begin{array}{c}\text { Total } \mathbf{t}_{\text {mix }} \\
(\mathbf{m i n})\end{array}$} & \multicolumn{6}{c}{ Mean Propellant $\begin{array}{c}\text { Slurry } \\
\text { (g//ml) }\end{array}$} \\
\cline { 2 - 7 } & $\mathbf{B}$ & SA & SB & SC & SD & T \\
\hline $\mathbf{9 5}$ & 1.595 & 1.596 & 1.587 & 1.655 & 1.653 & 1.611 \\
$\mathbf{1 1 5}$ & 1.502 & 1.549 & 1.565 & 1.555 & 1.546 & 1.495 \\
$\mathbf{1 3 5}$ & 1.528 & 1.590 & 1.601 & 1.570 & 1.525 & 1.514 \\
$\mathbf{1 5 5}$ & 1.629 & 1.592 & 1.554 & 1.594 & 1.607 & 1.633 \\
$\mathbf{1 7 5}$ & 1.485 & 1.624 & 1.531 & 1.621 & 1.523 & 1.536 \\
$\mathbf{1 9 5}$ & 1.595 & 1.620 & 1.650 & 1.672 & 1.630 & 1.583 \\
$\mathbf{2 1 5}$ & 1.517 & 1.565 & 1.561 & 1.550 & 1.471 & 1.535 \\
\hline \hline
\end{tabular}

TABLE 2.

DATA RESULT OF SOLID PROPELLANT DENSITY

\begin{tabular}{ccccccc}
\hline \hline \multirow{2}{*}{$\begin{array}{c}\text { Total } \\
\mathbf{t} \\
\text { (mix } \\
\text { (min) }\end{array}$} & \multicolumn{6}{c}{$\begin{array}{c}\text { Mean Solid Propellant Density at Spesified Location } \\
\text { (g/ml) }\end{array}$} \\
\cline { 2 - 7 } & $\mathbf{B}$ & SA & SB & SC & SD & T \\
\hline $\mathbf{9 5}$ & 1.349 & 1.365 & 1.375 & 1.358 & 1.368 & 1.379 \\
$\mathbf{1 1 5}$ & 1.451 & 1.381 & 1.416 & 1.394 & 1.407 & 1.381 \\
$\mathbf{1 3 5}$ & 1.423 & 1.391 & 1.404 & 1.427 & 1.415 & 1.424 \\
$\mathbf{1 5 5}$ & 1.431 & 1.425 & 1.429 & 1.426 & 1.401 & 1.418 \\
$\mathbf{1 7 5}$ & 1.426 & 1.438 & 1.458 & 1.436 & 1.438 & 1.448 \\
$\mathbf{1 9 5}$ & 1.408 & 1.419 & 1.406 & 1.441 & 1.416 & 1.435 \\
$\mathbf{2 1 5}$ & 1.459 & 1.459 & 1.424 & 1.439 & 1.498 & 1.445 \\
\hline \hline
\end{tabular}

Table 1 showed that the mean value of propellant slurry density was relatively same in each location for all mixing time variables. The same result was obtained for solid propellant density in table 2. It showed that the mean density in each location was relatively same and not much different. This statements were proofed by conducting t-test of two mean in each part of mixer. It can be found an information whether the density in each part of mixer was different or not. The result of t-test was stated that there was no differences of density value in each part of the mixer, so it can be said that the location of slurry in the mixer didn't affect the density value whether propellant slurry density or solid propellant density. Also can be said that every batch produced relatively homogeneous slurry, but to find the the most homogeneous slurry it need to do data processing.

Data processing was referred to statistical data. Density measurement provide the following data. Mean, variance, and standard deviation of the propellant slurry density and solid propellant density were showed in the table 3 and table 4 respectively.

TABLE 3.

DATA RESULT OF PROPELLANT SLURRY DENSITY

\begin{tabular}{cccccccc}
\hline $\begin{array}{c}\text { Total } \\
\text { tmix } \\
\text { (min) }\end{array}$ & $\mathbf{9 5}$ & $\mathbf{1 1 5}$ & $\mathbf{1 3 5}$ & $\mathbf{1 5 5}$ & $\mathbf{1 7 5}$ & $\mathbf{1 9 5}$ & $\mathbf{2 1 5}$ \\
\hline $\bar{y}$ & 1.61611 & 1.53550 & 1.55483 & 1.60155 & 1.55356 & 1.62505 & 1.53311 \\
$s^{2}$ & 0.00274 & 0.00342 & 0.00430 & 0.00338 & 0.00669 & 0.00644 & 0.00370 \\
$s$ & 0.05233 & 0.05846 & 0.06554 & 0.05817 & 0.08177 & 0.08025 & 0.06083 \\
\hline \hline
\end{tabular}


TABLE 4.

DATA RESULT OF SOLID PROPELLANT DENSITY

\begin{tabular}{llllllll}
\hline \hline $\begin{array}{l}\text { Total } \\
(\mathbf{m i n})\end{array}$ & $\mathbf{9 5}$ & $\mathbf{1 1 5}$ & $\mathbf{1 3 5}$ & $\mathbf{1 5 5}$ & $\mathbf{1 7 5}$ & $\mathbf{1 9 5}$ & $\mathbf{2 1 5}$ \\
\hline $\bar{y}$ & 1.36559 & 1.40510 & 1.41400 & 1.42161 & 1.44058 & 1.42083 & 1.45405 \\
$s^{2}$ & 0.00035 & 0.00104 & 0.00021 & 0.00025 & 0.00031 & 0.00028 & 0.00102 \\
$s$ & 0.01874 & 0.03217 & 0.01465 & 0.01570 & 0.01772 & 0.01663 & 0.03189 \\
\hline \hline
\end{tabular}

Data in the table 3 and table 4 were analyzed by one way anova to get information that the density data were significantly different with the change of mixing time. So, it can be confirmed that the mixing time was affect the density value.

One way anova test with significance value $1 \%$ has been done, the result showed that there was a significant differences of density value with the change of mixing time for both propellant slurry density and solid propellant density. So, the mixing time affect the density value and it can be confirmed that mixing time affect the homogeneity of slurry final mixing product.

Coefficient of variance $(c v)$ is used to state the diversity of data [9]. $c v$ was determined as a critical value evaluating the quality of mixing process [11]. A data set with small $c v$ value means that the data set have low diversity or can be said that one of the data to another was not much different. $c v$ value was expressed in percentage and it is showed in the table 5 and table 6.

TABLE 5.

DEGREE OF HOMOGENEITY OF PROPELLANT SLURRY DENSITY

\begin{tabular}{lllllllll}
\hline \hline & \multicolumn{8}{c}{ Total Mixing Time (minutes) } \\
& $\mathbf{9 5}$ & $\mathbf{1 1 5}$ & $\mathbf{1 3 5}$ & $\mathbf{1 5 5}$ & $\mathbf{1 7 5}$ & $\mathbf{1 9 5}$ & $\mathbf{2 1 5}$ & (155 \\
\hline $\begin{array}{l}c v(\%) \\
\begin{array}{l}\text { Degree of } \\
\text { homogeneity (\%) }\end{array}\end{array}$ & 9.238 & 3.807 & 4.215 & 3.632 & 5.264 & 4.938 & 3.968 \\
\hline \hline
\end{tabular}

TABLE 6.

DEGREE OF HOMOGENEITY OF SOLID PROPELLANT DENSITY

\begin{tabular}{llllllll}
\hline \hline & \multicolumn{6}{c}{ Total Mixing Time (minutes) } \\
\cline { 2 - 8 } & $\mathbf{9 5}$ & $\mathbf{1 1 5}$ & $\mathbf{1 3 5}$ & $\mathbf{1 5 5}$ & $\mathbf{1 7 5}$ & $\mathbf{1 9 5}$ & $\mathbf{2 1 5}$ \\
\hline \multirow{2}{*}{$\begin{array}{l}\text { (\%) } \\
\text { degree of homogeneity }\end{array}$} & 1.373 & 2.290 & 1.036 & 1.104 & 1.230 & 1.170 & 2.193 \\
(\%) & 98.62 & 97.71 & 98.96 & 98.89 & 98.77 & 98.83 & 97.80 \\
\hline
\end{tabular}

As the $c v$ value determine the diversity of data, the uniformity of data can be determined by the rest percentage. This can be stated as degree of homogeneity. Increasing in $c v$ value stated that the condition of slurry final mixing product are less homogeneous. Table 5 showed that degree of homogeneity value was relatively high, above 94\%, but for solid propellant density degree of homogeneity obtained in table 6 was higher, above $97 \%$. It means the diversity data of solid propellant density was lower than diversity data of propellant slurry density, because the instrumentation measurement result more reliable data processing.

The condition with the smallest value of $c v$ was to be satisfied as optimum condition. From table 6, the smallest $c v$ value was obtained at total mixing time 135 minutes, with the $c v$ value was $1.036 \%$ and degree of homogeneity 98.964\%.

The effect of mixing time to propellant slurry density was showed in figure 5 . The mean propellant slurry density and $c v$ value were very fluctuative. It can be caused by the rough method of the measurement. For propellant slurry, the density measurement was conducted manually by weighing slurry sample in well-know volume of mini slab. This manual method was done because the instrumentation only for density measurement of solid and liquid materials, but not for the slurry. The result of this manual measurement surely has more error than instrumentation measurement, so it less reliable than the solid propellant density data. So the solid propellant density was considered to determine the optimum condition that produce the most homogeneous slurry of final mixing product.

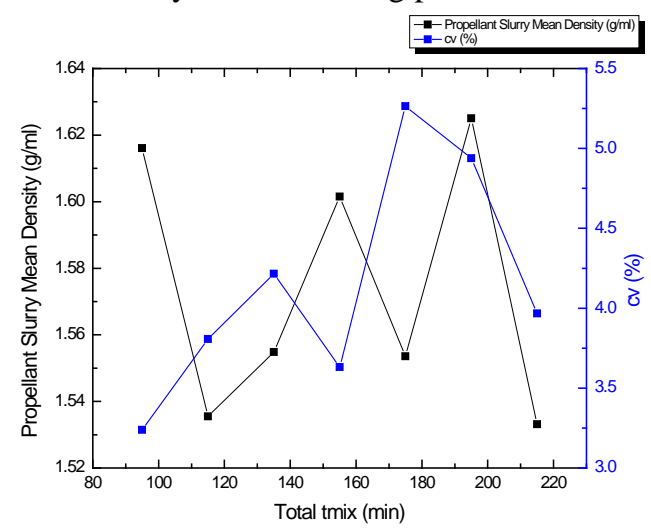

Figure 5. Change of Propelant Slurry Density and $c v$ to Total Mixing Time

The effect of mixing time to solid propellant density was showed in figure 6 . It appears that the $c v$ value was fluctuating as increased of mixing time, but relatively same yalue at 135, 155, 175, and 195 minutes of total mixing time. It means that those conditions of process produce propellant with relatively same value of density than the other condition, so the slurry was relatively homogeneous in those conditions.

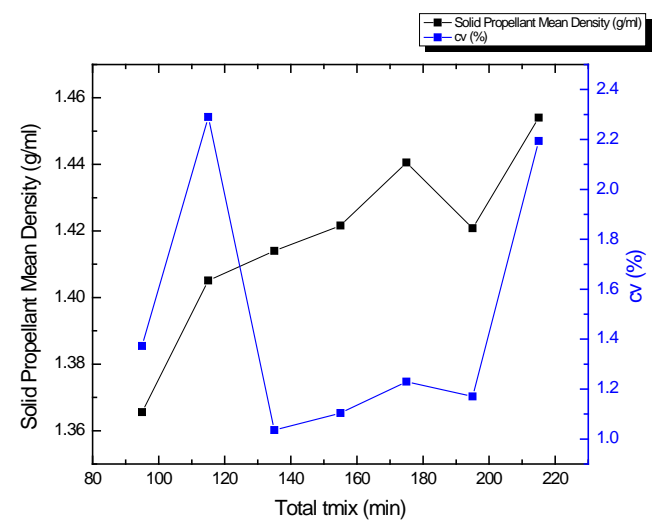

Figure 6. Change of Solid Propelant Density and $c v$ to Total Mixing Time

After the optimum condition raised, the $c v$ value were increasing, so the homogeneity of slurry was decreasing. The value of solid propellant density was relatively increasing with the addition of mixing time. It can be caused by the decreasing of homogeneity, so there was possibility that in the measured slurry sample were more solid materials. It make the density value higher and less in homogeneity. 
The $3^{\text {rd }}$ International Seminar on Science and Technology August $3^{\text {rd }}$ 2017, Postgraduate Program Institut Teknologi Sepuluh Nopember, Surabaya, Indonesia

\section{CONCLUSION}

The mixing time affects the homogeneity of slurry, which expressed in the presence of a significant change of solid propellant density in change of mixing time. The solid propellant density tend to increase as addition of mixing time i.e from $1.366 \mathrm{~g} / \mathrm{ml}$ at mixing time 95 minutes to 1.454 $\mathrm{g} / \mathrm{ml}$ at mixing time $215 \mathrm{~min}$, but decrease in homogeneity that was showed by increasing of $c v$ value. The most homogeneous slurry was obtained at mixing time 135 minutes with the degree of homogeneity $98.964 \%$.

\section{ACKNOWLEDGEMENT}

The authors gratefully acknowledge financial support from Indonesian National Institute of Aeronautics and Space (LAPAN) through LAPAN Master Scholarship Programme. Special thanks go to the Formulation Team for helping the work.

\section{REFERENCES}

[1] B. L. Gupta, V. Kumar, and N. Shivhare, "Rheological Studies on Virgin, Plasticized and Solid Filled HTPB Binder System," Glob. J. Adv. Eng. Technol. Sci., vol. 1, no. 2, pp. 41-48, 2014.
[2] G. P. Sutton and O. Biblarz, Rocket Propulsion Elements. New York: John Wiley \& Sons Inc, 2001.

[3] A. Davenas, Solid Rocket Propulsion Technology. Oxford: Elsevier Science, 1993.

[4] S. (Stanley) Fordham, High explosives and propellants. Oxford: Pergamon Press, 1980.

[5] A. W. Nienow, M. F. Edwards, and N. Harnby, Mixing in the Process Industries: Second Edition. Oxford: Elsevier Science, 1997.

[6] K. Miyanami, "Mixing," in Powder Technology Handbook, H. Masuda, K. Higashitani, and H. Yoshida, Eds. CRC Press, 2006.

[7] E. S. Szalai, M. M. Alvarez, and F. J. Muzzio, "Laminar Mixing: A Dynamical Systems Approach," in Handbook of Industrial Mixing, Hoboken, NJ, USA: John Wiley \& Sons, Inc., pp. 89-143.

[8] R. Weinekötter and H. Gericke, Mixing of Solids. Netherlands: Springer, 2000.

[9] W. D. Ergle and R. E. Walpole, Student study guide, Introduction to statistics, Ronald E. Walpole, 3rd edition. New York: Macmillan, 1982.

[10] J. S. Curtis, "Slurry Transport," in Introduction to Particle Technology, Rhodes, Martin., Chichester, UK: John Wiley \& Sons, Ltd, 2008, pp. 91-116.

[11] K. Zawiślak, J. Grochowicz, and P. Sobczak, "The Analysis of Mixing Degree of Granular Products With the Use of Microtracers," TEKA Kom. Mot. i Energ. Roln., no. 1, pp. 335-342, 2011. 